УДК $550.343+550.388+537.874$

\title{
АНОМАЛИИ ВО ВРЕМЕННОМ РАСПРЕДЕЛЕНИИ СООТНОШЕНИЯ СПЕКТРАЛЬНЫХ ПЛОТНОСТЕЙ АТМОСФЕРИКОВ В ПЕРИОД ПОДГОТОВКИ ЗЕМЛЕТРЯСЕНИЙ ПРИ ИСПОЛЬЗОВАНИИ СЕЛЕКЦИИ ПО УГЛАМ ПРИХОДА
}

\author{
В. В. Кабанов, И. М. Хасанов \\ ФГБУН Северо-Восточный комплексный научно-исследовательский институт \\ им. Н. А. Шило ДВО РАН, г. Магадан \\ E-mail: vvk20062@yandex.ru, hasanov@neisri.ru
}

\begin{abstract}
При анализе данных землетрясения магнитудой $\mathrm{M}=5.6$, произошедшего на юго-востоке Якутии 20.01.2013 г., с применением угловой селекции приходящих атмосфериков обнаружены дополнительные предвестники этого землетрясения, ближайшие за 10 мин до толчка. На основе анализа серии землетрясений на о. Кюсю в апреле 2016 г. выявлен комплекс аномалий во временном распределении соотношения спектральных плотностей (ССП) естественных электромагнитных сигналов (атмосфериков) для верхнего и нижнего поддиапазонов принимаемой полосы частот (8-40 кГц) электромагнитного поля. Элементы этого комплекса аномалий обнаружены во временном распределении ССП атмосфериков, приходящих с направления на эпицентр, перед тремя землетрясениями с $\mathrm{M}<5$, произошедшими на расстоянии 60-220 км от Магадана. Перед землетрясением 07.05.2016 г. с M $=4.7$ наблюдается период пониженных значений дневных минимумов ССП в дневное время и выбросы ССП. Землетрясению 22.02.2016 г. с М = 4.1 предшествует короткий период пониженных значений дневных минимумов и вечерний выброс ССП. Перед землетрясением 12.12.2005 г. отмечаются возрастающие вечерние выбросы ССП. Использование угловой селекции атмосфериков при оценке ССП позволяет обнаружить дополнительные аномалии во временном распределении ССП перед предстоящим землетрясением и возможные предвестники перед землетрясениями с $\mathrm{M} \approx 4$.
\end{abstract}

Ключевые слова: землетрясения, электромагнитные сигналы, атмосферики, соотношение спектральных плотностей, предвестники.

DOI: $10.34078 / 1814-0998-2020-1-81-93$

\section{ВВЕДЕНИЕ}

В 2004-2012 гг. на территории Магаданской области функционировала сеть региональных станций сейсмоэлектромагнитного мониторинга (СЭМ), осуществляющая регистрацию электрической компоненты электромагнитного (ЭМ) поля в ОНЧ-НЧ диапазоне (8-40 кГц) (Шарафутдинов, Кабанов, 2007), наблюдаемого на станциях, размещенных в пос. Омчак, Сеймчан и Стекольный. Анализ записей станций перед землетрясением с магнитудой 5.4, произошедшим 03.08.2010 г. на глубине 33 км, позволил разработать новую методику обнаружения предвестников землетрясений на основе анализа аномалий в соотношении спектральных плотностей (ССП) атмосфериков для разных станций на верхних частотах исследуемого диапазона (Кабанов, Шара-

(C) Кабанов В. В., Хасанов И. М., 2020 футдинов, 2013). Новизна методики заключается в использовании информации о спектре атмосфериков в отличие от анализа амплитуд атмосфериков (АА) или интенсивности их потока (Каталог..., 1991; Муллаяров и др., 2011; Mullayarov et al., 2012), а также информации с разнесенных станций.

С 2013 г. функционирует система обнаружения аномалий в ЭМ поле в реальном времени на базе двух станций, размещенных в пос. Стекольный и г. Магадан, с использованием предобработки сигнала на станции «Стекольный» с последующей передачей результатов через интернет в Магадан для совместной обработки данных двух станций. Эта система позволяет обнаруживать предвестники землетрясений при анализе ССП для верхних и нижних поддиапазонов исследуемых частот (Кабанов, 2013). Для землетрясения $\mathrm{M}=5.6$, произошедшего на юго-востоке Якутии 20.01.2013 г., обнаружены предвестники в виде 
сужения основного дневного минимума ССП атмосфериков за 3-4 сут до землетрясения и уменьшения амплитуды дневного минимума ССП за 1-2 сут (Кабанов, 2013). Позднее для этого землетрясения был выполнен более полный анализ всех записанных данных, показавший перспективы рассмотрения зависимостей ССП атмосфериков с учетом их угла прихода. Угловую селекцию ранее использовали в работах (Муллаяров и др., 2011; Mullayarov et al., 2012) при исследовании АА, проходящих над областями землетрясений. Основы этого метода заложены В. А. Муллаяровым с соавторами (2007).

При анализе аномалий ССП перед серией землетрясений на о. Кюсю (Япония) был обнаружен новый тип предвестников в виде композиции аномалий в ССП (слабая искаженность и пониженные дневные уровни в период перед землетрясениями с последующим их возрастанием и возникновением дневных выбросов ССП к моменту начала серии землетрясений), которые при использовании селекции по углу прихода атмосфериков были найдены и перед местными землетрясениями с $\mathrm{M}=4.1$ и $\mathrm{M}=4.7$, произошедшими соответственно 22.02.2016 г. в 85 км к северо-востоку от Магадана и 07.05.2016 г. на расстоянии 220 км к западу от Магадана.

\section{АППАРАТУРА И МЕТОДИКА ИССЛЕДОВАНИЙ}

В качестве исходных данных используются записи электрической компоненты электромагнитного (ЭМ) поля в диапазоне 8-40 кГц. Регистрация осуществляется с помощью специально разработанных комплексов (Кабанов, Шарафутдинов, 2007). В установленном на антенной мачте выносном приемном устройстве производится усиление сигнала, его преобразование на промежуточную частоту 108-140 кГц и передача через коаксиальный кабель на центральный блок приемного устройства, в котором происходит обратное преобразование частоты и усиление сигнала для подачи на аналогово-цифровой преобразователь (АЦП). Синхронизация преобразователей частоты выполняется с использованием гетеродинов, согласованных с сигналом от термостатируемого кварцевого генератора. Сигнал оцифровывается с частотой 100 кГц. Используется двухканальный АЦП, на второй вход подаются следующие с частотой 1 Гц импульсы от GPS-приемника. Передний фронт импульса соответствует началу секунды. Для регистрации используется ноутбук с двухъядерным процессором «Atom». Сигнал непрерывно записывается на диск с сохранением последних данных и перезаписью более старых (давность 6 сут). А для поступающих от GPS-приемника импульсов производится обработка, в ходе которой определяется временное положение импульсов и запись этих данных на диск в отдельные файлы (рис. 1).

Обработка в целом основывается на методике, разработанной В. В. Кабановым и В. М. Шарафутдиновым (2013). Но, в отличие от этой методики, поиск атмосфериков выполняется уже при предварительной обработке на основе корреляции записанного сигнала с образцом типичного атмосферика. Определяются временное положение атмосферика и значения спектральной плотности мощности для частотных диапазонов 8-12, 12-20, 20-30 и 35-40 кГц. Полученные оценки записываются в специальные файлы, которые передаются с периферийной станции через интернет. Анализ выполняется для 2-минутных записей каждые 15 мин. Кроме того, каждые 2 мин оценивается уровень сигнала расположенной в Японии (префектура Фукушима) радиостанции с частотой 40 кГц, что также может быть полезно для поиска предвестников землетрясений (Кабанов, Хасанов, 2016). На центральной станции функции предварительной обработки обеспечиваются центральным компьютером с многоядерным процессором. Передача данных между компьютерами осуществляется с помощью технологии Wi-Fi. На центральном компьютере выделяются атмосферики, одновременно наблюда-
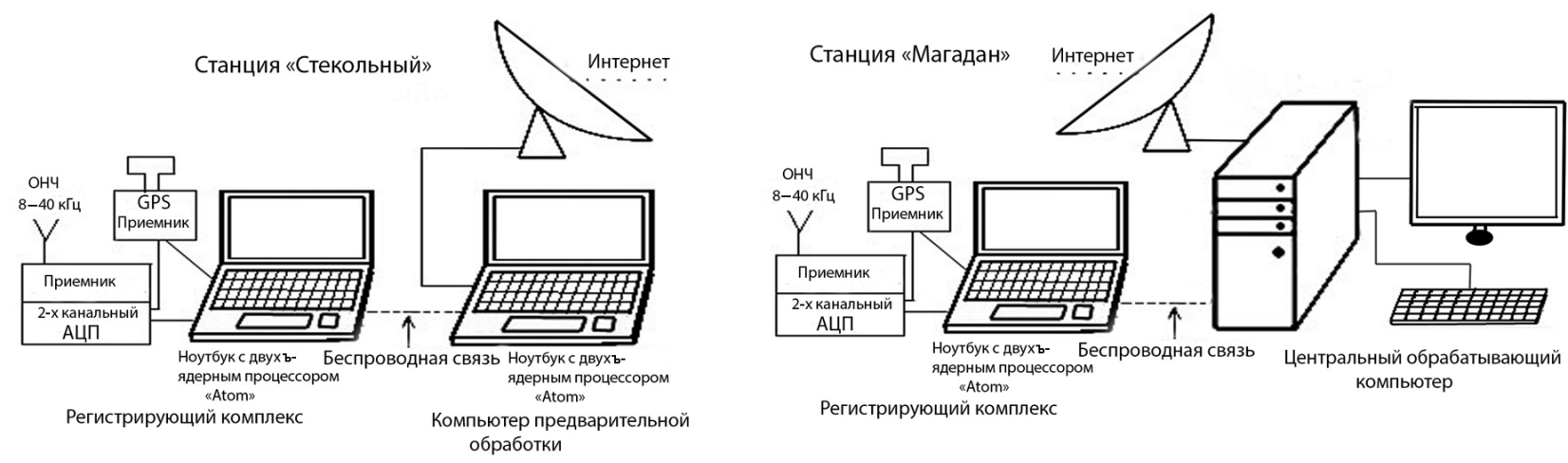

Puc. 1. Схема системы для поисков электромагнитных предвестников землетрясений в реальном масштабе времени

Fig. 1. System scheme for the search of the earthquakes electromagnetic precursors in real time 
емые на двух станциях, которые используются для дальнейшего определения ССП. Одновременно оценивается разница времени прихода атмосфериков на станции, что позволяет разделить поток атмосфериков по направлениям прихода на станции. Максимальная разница прихода для данного расположения станций составляет 170 мкс (17 интервалов дискретизации АЦП), поэтому из-за ошибок определения положения атмосфериков разделение по направлениям прихода не очень точное. Если для широтного направления при ошибке определения задержки прихода на 10 мкс (1 интервал дискретизации) неточность определения угла прихода всего $3.4^{\circ}$, то для меридионального направления такое отклонение в определении задержки приведет к ошибке определения угла $19.7^{\circ}$. Но даже такое разделение позволяет получить новые результаты по отношению к анализу без использования угловой селекции.

Для отобранных атмосфериков рассчитывается ССП для верхних (35-40 кГц) и нижних (1220 кГц) частот. Выбрана не самая нижняя полоса (8-12 кГц), в этом поддиапазоне существенное влияние оказывает температура окружающей среды на фильтры приемника. Как показали исследования, неискаженная зависимость ССП от времени имеет регулярный вид в случае использования для анализа атмосфериков, приходящих с южных направлений. Именно эту зависимость мы использовали для выделения параметров временного распределения ССП, связанных с землетрясениями. Кроме того, определяли зависимость выделенных параметров от угла прихода атмосфериков.

Зависимость ССП обычно характеризуется ночным максимумом и дневным минимумом для местного времени LT $=\mathrm{UT}+12$ ч. Переход от низких дневных значений к высоким ночным быстро происходит в предполуночное время. А обратный переход, так же быстро, совершается за несколько часов до полудня. Конкретное время переходов зависит от сезона года. В связи с определяющим влиянием местного времени на вид ССП далее везде показаны зависимости ССП от LT и обозначены моменты землетрясений. Типичные искажения временной зависимости ССП атмосфериков выражаются в наличии выбросов ССП в дневное время. Эти выбросы связаны с вариациями мировой грозовой активности и нестабильностью условий распространения радиоволн для верхней части исследуемого диапазона частот. Аналогично могут происходить колебания среднего уровня значений ССП и повышения уровней значений ССП в дневное время. Но перед землетрясениями наблюдается необычная совокупность таких аномалий.

\section{РЕЗУЛЬТАТЫ АНАЛИЗА}

При анализе временного распределения ССП перед землетрясением 20.01.2013 г. на юге Якутии были обнаружены начинающиеся за 4 сут отклонения (сужения дневного минимума ССП атмосфериков и уменьшения амплитуды дневного минимума) от типичной формы (устойчивый максимум в ночное время и минимум в дневное с амплитудой 2-4 дБ, примерно соответствующие по длительности темному и светлому временам суток) зависимости (Кабанов, 2013). Этот результат был получен при оперативном анализе всех атмосфериков, одновременно зарегистрированных на станциях Магадан и Стекольный в январе 2013 г. Позднее была разработана программа для анализа временного распределения ССП в выбираемых секторах углов прихода атмосфериков. Был выполнен анализ для временного интервала в несколько суток перед землетрясением в разных секторах углов. И при секторе углов прихода атмосфериков, ориентированных в сторону землетрясения (28-40 ${ }^{\circ}$ от северного направления), был обнаружен выброс ССП непосредственно перед землетрясением. Зафиксированный выброс соответствовал резкому падению интенсивности потока атмосфериков в этом секторе углов, в связи с чем был выполнен дополнительный непрерывный анализ всех записанных реализаций (каждой минуты, в отличие от оперативного, когда анализируются 2 мин каждые 15 мин). Результаты анализов приведены на рис. 2 . Показано временное распределение ССП для атмосфериков, приходящих в Магадан с задержкой 13-15 интервалов квантования АЦП (130150 мкс). Такая задержка соответствует сектору углов $28-40^{\circ}$ от северного направления. На врезке рис. 2 приведены результаты оперативного анализа для периода 12-23.2013 г., а на самом рисунке показаны результаты непрерывного анализа для интервала с 11:00 20.01 по 06:00 21.01. Выброс ССП за 10 мин перед землетрясением соответствует имеющемуся на врезке рис. 2. Кроме того, на рис. 2 имеются еще два выброса в интервале 15 ч перед землетрясением. Выбросы меньшей амплитуды наблюдаются и после землетрясения (см. врезку на рис. 2). Также на врезке за 3 сут перед землетрясением наблюдаются эффекты, отмеченные В. В. Кабановым (2013) при анализе всех атмосфериков. Выбросы ССП, показанные на рис. 2, не являются уникальными при анализе узком диапазоне задержек. Так, для использованного направления ближайший похожий имеется за 0.5 мес перед землетрясением, а после землетрясения наблюдается через месяц. Был просмотрен двухгодичный временной интервал для записей в октябре - апреле 2012 2016 гг. Анализировались зимние записи, по- 


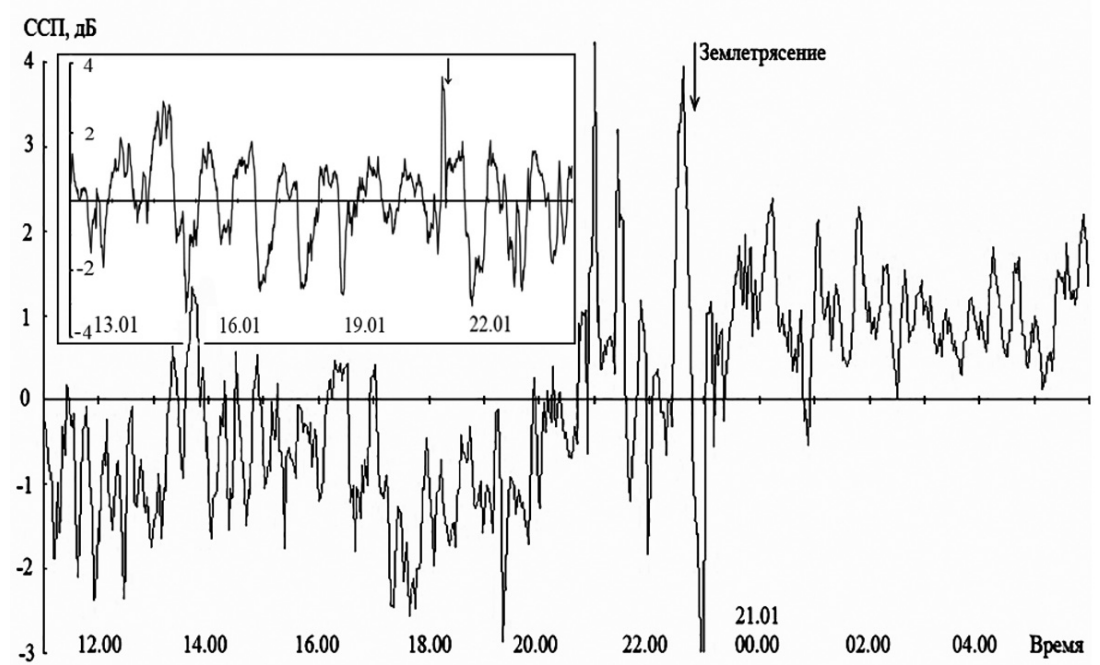

Рис. 2. Временное распределение ССП 20-21.01.2013 для атмосфериков с задержкой 13-15 интервалов дискретизации (130-150 мкс, сектор углов $28-40^{\circ}$ от северного направления), полученное при поминутном анализе, и 12-23.01.2013, полученное при оперативном (врезка)

Fig. 2. Temporal distribution of the SDR on January 20-21, 2013, for atmospherics with delay of 13-15 sampling intervals (130-150 $\mu \mathrm{s}$, sector of corners $28-40^{\circ}$ from the northern direction), obtained by per-minute analysis, and $12-$ 23.01.2013, obtained in the operational (inset)

скольку похожие выбросы могут наблюдаться и вследствие региональных (до 1000 км) гроз. Найдено около 40 случаев похожих выбросов. Если предположить случайный характер их возникновения, то интенсивность потока таких событий составит примерно 0.00006 ч$^{-1}$ и вероятность наблюдения выброса в 2-часовом интервале перед землетрясением 0.00012. Это свидетельствует в пользу связи наблюдаемого эффекта с готовящимся землетрясением.

Другим примером использования угловой селекции атмосфериков является комплекс аномалий ССП перед серией землетрясений на о. Кюсю (Кабанов, 2019). При этом использовали не жесткую селекцию, а просто отбор атмосфериков, приходящих с южных направлений (плюс-минус 90).

На рис. 3 показано распределение ССП для временного интервала 28.02-25.04 2016 г. (Там же), с разметкой периодов аномалий. Вначале возникает период пониженных значений дневных минимумов ССП (минимумысоединеныпунктирными линиями 1). Затем, за 3 нед до начала серии землетрясений, значения дневных минимумов еще немного понижаются (пунктирные линии 2) и зависимость характеризуется слабой возмущенностью (очень слабые выбросы ССП в дневное время, пунктирные линии 3). На рис. 3 в качестве примера отмечены также периоды более высокой возмущенности зависимости ССП (линии 6). Линии 6 расположены выше линий 3 , и отклонения ССП от них больше (в дневное время, естественно). За 3 сут до начала серии начинается возрас-

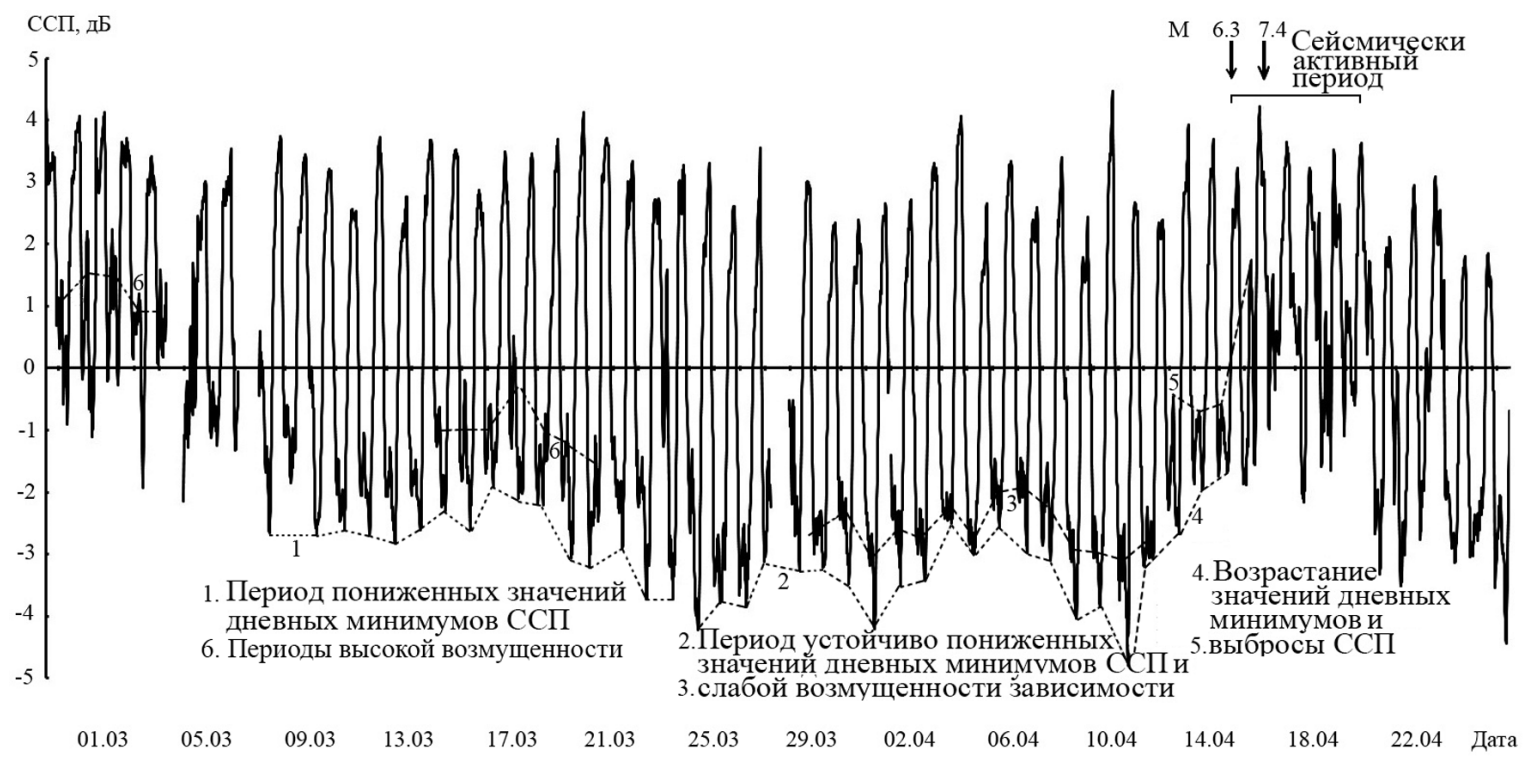

Рис. 3. Временное распределение ССП южных атмосфериков для 28.02-25.04 2016 г. Стрелками показаны моменты первых землетрясений

Fig. 3. Temporal distribution of the SDR for southern atmospherics for February 28 - April 25, 2016. The arrows indicate the moments of the first earthquakes 
тание значений дневных минимумов (линии 4) и возникают дневные выбросы ССП (линии 5). Наиболее высокий выброс наблюдается перед вторым, самым сильным землетрясением серии. Комплекс аномалий, а именно - понижение значений дневных минимумов, слабая возмущенность зависимости, повышение значений дневных минимумов и выбросы ССП непосредственно перед землетрясениями представляется предвестником этой серии землетрясений (Кабанов, 2019). При анализе уже упомянутого двухгодичного временного интервала такого сочетания аномалий по порядку следования и длительности больше не обнаружено. Найденная совокупность аномалий ССП явилась ключом к обнаружению нетипичного поведения ССП и перед двумя региональными землетрясениями.

На рис. 4 показано распределение ССП для временного интервала 22.04-07.05.2016 г. (рис. 4,a) и 2015 г. (рис. 4,б). 07.05.2016 г. в 00:46:31 условного LT $(\mathrm{GT}+12)$ произошло землетрясение к западу от Магадана на расстоянии около 220 км, примерно одинаковом для станций в Магадане и на Стекольном. Магнитуда землетрясения по данным Службы срочных донесений Геофизической службы РАН равняется 4.7. Для такого землетрясения радиус ионосферных возмущений составляет чуть более 100 км и суще- ственно меньше расстояния до станций. Поэтому в зависимости ССП от времени для южных атмосфериков, показанных на рис. 4, $a$, заметных аномалий практически не наблюдается. Но ситуация существенно меняется при рассмотрении распределения ССП для атмосфериков, приходящих из сектора углов, направленного в сторону землетрясения (с запада, с задержками в диапазоне плюс-минус 20 мкс, т. е. 2 интервала квантования АЦП, что соответствует сектору углов $14^{\circ}$ ).

При рассмотрении ССП для атмосфериков с западного направления на рис. 4,a можно заметить наличие периода пониженных значений дневных минимумов (соединены пунктирными линиями 1) ССП (на величины до 2 дБ относительно 22-24.04), начинающийся с 27.04.2016 г. С 04.05.2016 г. (перерыв в записях связан с неисправностью комплекса на Стекольном) появляются выбросы (линии 2) ССП в дневное время. Выброс наибольшей амплитуды отмечается 06.05, в день перед землетрясением. Наибольшее различие между ССП для атмосфериков, приходящих с западного и южного направления, проявляется в амплитуде дневных минимумов 27-29.04 и в амплитуде выброса перед землетрясением.

Наблюдаемые для приходящих с запада атмосфериков аномалии частично схожи с наблюдаемыми перед серией землетрясений на юге

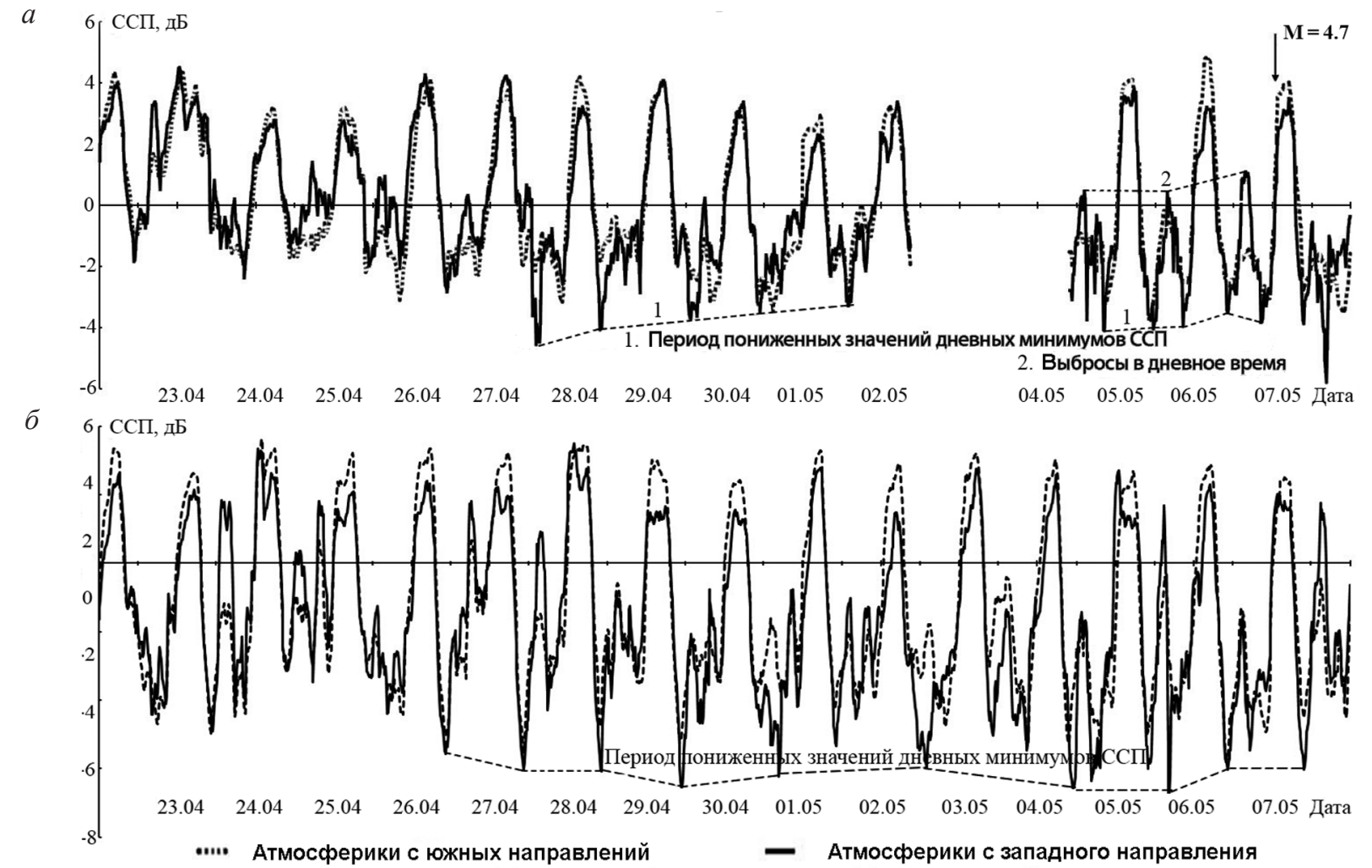

Рис. 4. Временные распределения ССП западных и южных атмосфериков для 22.04-07.05 2016 г. (a) и 2015 г. (б)

Fig. 4. Temporal distributions of the SDR for western and southern atmospherics for April 22 - May 7, 2016 (a) and 2015 (б) 
Японии (см. рис. 3). Но если те аномалии оказываются уникальны при просмотре всех записей 2012-2016 гг., то для аномалий перед рассматриваемым местным землетрясением (всего по двум параметрам) этого нет, похожие участки попадаются. Более того, в случае рассмотрения аналогичного периода 2015 г., поведение ССП для которого приведено на рис. 4,б, присутствуют как пониженные значения дневных минимумов (с 26.04.2015), так и выбросы (5.05 и 7.05), хотя понижение амплитуды дневных минимумов на рис. 5 меньше, чем на рис. 4 (около 1 дБ относительно 22-23.04). Понижение амплитуд дневных минимумов также наблюдалось в этот же период 2013 г. (менее устойчивое), но отсутствовало в 2014 г. Таким образом, формирование аномалий на рис. 4, на первый взгляд, в значительной степени связано с сезонными изменениями в поведении ССП. Но различие установлено при анализе зависимости степени проявления аномалий от направления. Если для случая землетрясения (рис. 4,a) аномалии (понижение дневных минимумов и выброс 06.05) практически исчезают при смещении сектора углов анализа на $14^{\circ} \mathrm{\kappa}$ югу или северу, то для анализируемого временного отрезка 2015 г. (см. рис. 4,б) выброс 5.05 максимально проявляется для направления $17^{\circ} \mathrm{\kappa}$ северу, выброс 7.05 вообще максимален для почти северного направления, а понижение дневных минимумов 28-30.05 на рис. 4,6 наиболее четко фиксируется для сектора углов $17^{\circ}$ к югу. Таким образом, более детальный анализ зависимости поведения ССП от угла прихода атмосфериков показал отличие наблюдаемых перед землетрясением аномалий от имеющихся на рис. 4,б.

Также, если сравнить временные зависимости ССП на рис. 4, $a$ и 4,б в интервале 27.04-01.05, то для случая рис. $4, a$ можно отметить меньшую искаженность временной зависимости ССП (меньшая амплитуда выбросов) в дневное время, чем на рис. 4,б. Численно это выражается в меньшем среднеквадратичном отклонении (СКО) наблюдаемой временной зависимости ССП от типичной. При аппроксимации типичной зависимости симметричной относительно минимума кривой для 2013-2016 гг. получены значения СКО 1.4, $1.5,2.1$ и 1.2 соответственно. При учете несимметричности отклонений ССП от типичной зависимости значения СКО составили: $1.1,0.9,1.6$ и 0.5 в 2016 г. перед землетрясением. Для поведения ССП перед землетрясением в некоторой степени присуща и меньшая искаженность, как в случае серии землетрясений на о. Кюсю.

Поэтому, учитывая результаты анализа зависимости проявления аномалий от направления, меньшую искаженность и большее снижение амплитуды дневных минимумов ССП, влияние землетрясения на формирование аномалий в поведе- нии ССП на рис. 4, $a$ представляется наиболее вероятным.

При сужении интервала анализируемых углов до соответствующих плюс-минус 10 мкс (1 интервалу квантования АЦП), что соответствует сектору углов $7^{\circ}$, дневные выбросы ССП становятся выше, но существенно увеличивается изрезанность всей зависимости. Это связано с ошибками определения положения атмосфериков в данной системе из двух близко расположенных станций. При сужении угла обзора устраняются ошибочно попавшие атмосферики, но теряются истинные. Полноценный анализ с использованием угла прихода атмосфериков возможен только при наличии достаточно удаленных друг от друга станций. Поэтому на основе разработанной системы с использованием двух станций можно только определить принципы выделения предвестников землетрясений без достаточно полного их экспериментального подтверждения.

Можно также отметить, что при совместном рассмотрении зависимостей, представленных на рис. $4, a$, некоторые аномалии обнаруживаются и у распределения ССП для южных атмосфериков. С 30.04.2016 г. имеется период пониженных значений дневных минимумов и есть выбросы ССП перед землетрясением. Но выраженность этих аномалий соответствует аномалиям, наблюдаемым в обычное время. Поэтому судить об аномалиях ССП как о предвестниках данного землетрясения можно только при использовании селекции атмосфериков по углу их прихода.

22.02.2016 г. произошло землетрясение с $\mathrm{M}=4.1$ примерно в 85 км к востоку от станций на одинаковом расстоянии от них. В этом же районе расположен эпицентр землетрясения 12.12.2005 г., и для него найдены предвестники (Кабанов, Шарафутдинов, 2012). Для текущего землетрясения при рассмотрении распределения ССП для южных атмосфериков предвестников обнаружено не было. Но после обнаружения предвестников для землетрясения 07.05.2016 г. появилась идея рассмотреть случай землетрясения 22.02.2016 г. также с использованием селекции по углам. Поток атмосфериков с восточного направления нестабилен и очень мал, особенно в зимнее время. Но такие атмосферики наблюдались перед землетрясением 12.12.2005 г.

На рис. 5 приведены временные распределения ССП для южных и приходящих с диапазоном задержек в плюс-минус 3 интервала квантования АЦП (30 мкс), что соответствует сектору углов $20^{\circ}$ в широтном направлении, атмосфериков. На врезке показан растянутый участок зависимости для атмосфериков, приходящих на станции в секторе углов $20^{\circ}$ с 0 ч 21.02 по 12 ч 22.02 . Для этих атмосфериков перед землетрясением наблюдается приближение времени вечернего перехода 


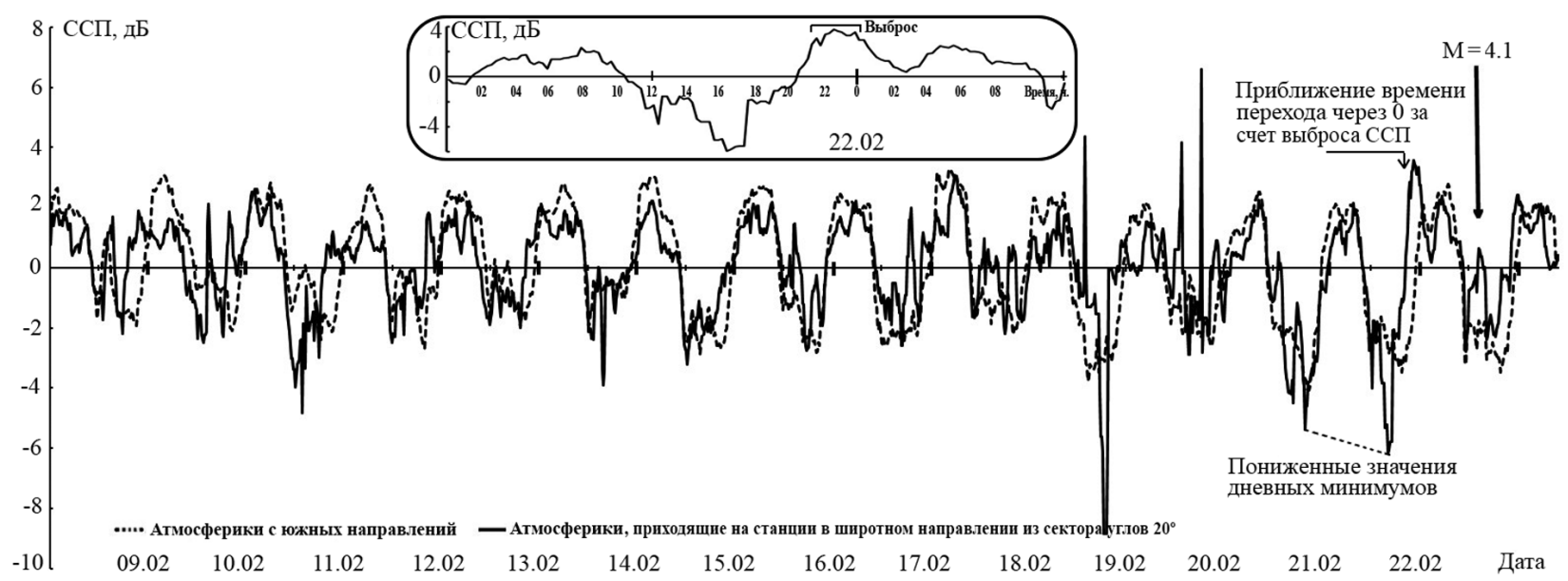

Puc. 5. Временные распределения ССП для южных и приходящих с приходящих на станции в широтном направлении из сектора углов $20^{\circ}$ атмосфериков для 08.02-22.02.2016 г.

Fig. 5. Temporal distributions of the SDR for southern atmospherics and those coming from the arriving at the station in the latitudinal direction from the sector of angles of $20^{\circ}$ for February 08-22, 2016

зависимости ССП через 0, аналогично случаю землетрясения 12.12.2005 г. (Кабанов, Шарафутдинов, 2012), хотя подобный эффект просматривается на рис. 5 и в другие дни (9-11.02, 16.02). Но перед землетрясением выброс ССП в вечернее время (как видно на врезке, начинается в 20:20 и имеет максимум около 23 ч) наиболее высокий и широкий. Еще узкие выбросы с большой амплитудой наблюдаются 18-19.02.2016 г., но их связь с землетрясением требует дополнительного специального анализа. А 20-21.02.2016 г. присутствует уже обнаруженная для других землетрясений аномалия - понижение минимумов ССП в дневное время на 2-4 дБ, аналогично случаям землетрясения 07.05.2016 г. (в 220 км от Магадана) и Японской серии. Совокупность аномалий ССП, выраженных как понижение дневного уровня за 2 сут, и приближение времени перехода через 0 за счет образования вечернего выброса могут быть признаны предвестниками данного землетрясения. В пользу этого свидетельствует и зависимость проявления аномалий от смещения сектора анализируемых углов. Выброс перестает наблюдаться при смещении сектора на $14^{\circ}$ к северу или югу (как в случае землетрясения в мае 2016 г.). Выраженность понижения дневных минимумов исчезает при смещении к северу на $10^{\circ}$ или к югу на $25^{\circ}$. Вне сектора плюс-минус $20^{\circ}$ исчезают и все узкие выбросы 18-19.02.

Обнаружение аномалий ССП перед землетрясением 22.02.2016 г. при анализе с применением угловой селекции атмосфериков наводит на мысль применить такой анализ и для землетрясения 12.12.2005 г. с M 4, произошедшего в 63 км к востоку от пос. Стекольный.

На рис. 6 приведены временные распределения ССП для этого землетрясения. Распределение для всех атмосфериков соответствует представленному в работе В. В. Кабанова и В. М. Шарафутдинова (2012). При селекции западных и восточных атмосфериков использовался тот же сектор углов, что и в случае, представленном на рис. 5. На рис. 6 совокупность вечерних выбросов ССП непосредственно перед землетрясением для западных и восточных атмосфериков (5 и 6) стала выше, чем в случае всех атмосфериков (5в и 6в). Также такие выбросы появились и в предыдущие дни. 09.12.2005 г. выброс 1 только намечается, через день выброс 3 уже четко выражен и достигает максимума перед землетрясением (выброс 5). Точнее, 10.12 и 11.12.2005 г. наблюдаются 2 выброса (3.4 и 5.6). 10.12.2005 г. выбросы 3 и 4 разделены четким минимумом, а 11.12.2005 г. перед землетрясением выбросы 5 и 6 практически сливаются. При выборе южных атмосфериков исключены углы, входящие в секторы восточных и западных. Поздний вечерний выброс отсутствует, а более ранний (5ю) едва выражен. Это подтверждает связь наблюдаемых выбросов с землетрясением, а не с изменениями характера грозовой активности.

\section{ОБСУЖДЕНИЕ РЕЗУЛЬТАТОВ}

Анализ распределения ССП в узком секторе углов перед землетрясением 20.01.2013 г. на юго-востоке Якутии (см. рис. 2) показывает наличие аномальных для включающего землетрясение 1.5-месячного временного интервала (фоновое поведение ССП аналогично участкам на рис. 2, не включающим выбросы) выбросов ССП для атмосфериков, приходящих на станции с задержкой 13-15 интервалов дискретизации (130150 мкс, сектор углов 28-40 правления). Если оценить размер зоны возмож- 


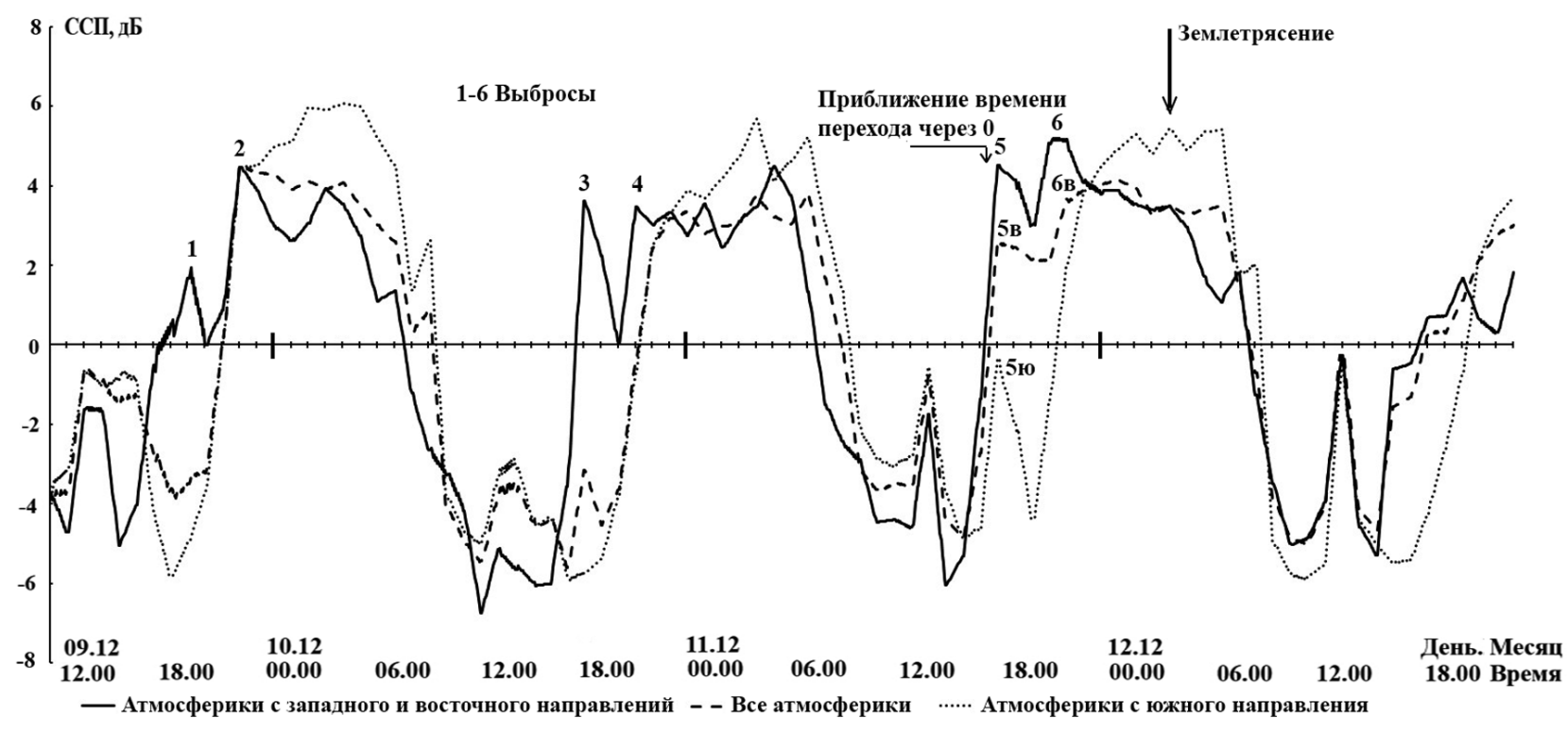

Рис. 6. Временные распределения ССП атмосфериков, приходящих с западного и восточного направлений, всех атмосфериков и атмосфериков с южного направления для 09.12-12.12.2005 г.

Fig. 6. Temporal distributions of the SDR for atmospherics, coming from the western and the eastern directions, all atmospherics, and atmospherics from the southern direction for December 9-12, 2005

ных ионосферных возмущений по экспоненциальной формуле (Кабанов, Шарафутдинов, 2012), то радиус этой зоны для $\mathrm{M}=5.6$ составит 270 км, т. е. граница находится посередине между станциями и эпицентром землетрясения. Выбранная задержка как раз соответствует этой границе. Поэтому физической причиной обнаруженного эффекта может быть отражение атмосфериков от границы зоны ионосферных возмущений перед землетрясением. Обнаружению эффекта способствовало расположение эпицентра землетрясения на пути атмосфериков, приходящих из Африканского центра грозовой активности. Если бы землетрясение произошло к северо-западу от станций, эффекта бы не было, поскольку интенсивность потока атмосфериков с этого направления очень мала.

Наиболее стабилен поток атмосфериков от юго-восточного Азиатского центра грозовой активности. Это позволило обнаружить предвестники серии землетрясений на о. Кюсю с использованием простой селекции южных атмосфериков. Физической причиной эффекта служит затенение грозового центра зоной ионосферных возмущений перед землетрясениями. Радиус зоны возмущений составляет 1500 км, и при расположении зоны примерно посередине между станциями и центром грозовой активности зона экранирует весь центр, поскольку его линейные размеры в широтном направлении не превышают 3000 км.

Для землетрясения 07.05.2016 г. эпицентр находится к западу от станций, и с учетом достаточной интенсивности потока атмосфериков с этого направления возникновение эффекта ис- кажения ССП для этих атмосфериков достаточно обосновано. А землетрясение 22.02.2016 г. произошло к востоку от станций, с этого направления поток атмосфериков нестабилен. В то же время зависимость ССП для этих атмосфериков (см. рис. 5) достаточно регулярна (за исключением выбросов 18-19.02). Это свидетельствует о преобладающем вкладе западных атмосфериков, и зависимость ССП для них подверглась влиянию землетрясения, произошедшего на востоке. Возможной причиной этого является вытянутость зоны ионосферных искажений в широтном направлении. Согласно, например, разработкам (Захаренкова и др., 2006; Пулинец и др., 2010), размер зоны искажений по долготе превышает размер по широте в 2.5-3 раза. При среднем радиусе зоны искажений около 60 км для $\mathrm{M}=4.1$ с учетом вытянутости она достаточно далеко простирается в западном направлении от станций, что и объясняет возникновение эффекта искажения ССП.

Обнаружение предвестников перед землетрясением с $\mathrm{M} \approx 4$ является самостоятельным результатом, при спутниковых исследованиях значение $\mathrm{M}=5$ служит границей, ниже которой аномалии не наблюдаются. Последний случай обнаружения предвестников при $\mathrm{M}=4$ описан в электронном журнале (Смирнов, 2003). В Каталоге (1991) приведены результаты значительно более ранних исследований, в том числе об обнаружении аномалий перед землетрясениями с $\mathrm{M}=4$ и менее. Но в этих работах высказываются суждения об обнаруженных аномалиях в интенсивности потока атмосфериков как о предвестниках только на 
основании их нахождения перед землетрясениями. Сведений о наличии аномалий на других временных интервалах не приводится. При наших наблюдениях с 2004 г. даже перед землетрясениями с $\mathrm{M}>5$ не регистрировалось флуктуаций интегрального потока атмосфериков, отличных от происходящих в остальное время, а также излучений из области подготовки землетрясений.

Следует также отметить, что землетрясение 12.12.2005 г. ощущалось существенно сильнее, чем 22.02.2016 г., хотя для первого по данным Магаданской сейсмостанции энергетический класс этого землетрясения меньше 11. Скорее всего, это связано с каким-то сбоем. В частности, в то время не работал GPS-приемник на сейсмостанции Омчак и время в компьютере сейсмостанции было сбито. О большей силе землетрясения 12.12.2005 г., чем 22.02.2016 г., свидетельствуют и более ярко выраженные аномалии ССП, отображенные соответственно на рис. 6 и 5. Для рассмотренных случаев с силой землетрясения связана и длительность периода пониженных значений дневных минимумов ССП. Для серии землетрясений на о. Кюсю (максимальная $\mathrm{M}=7.4$ ) этот период более 3 нед (см. рис. 3), для землетрясения 07.05.2016 г. с М = 4.7 период пониженных значений начинается за 10 сут до толчка (см. рис. 4,a), хотя и не уникален для данного сезона года (см. рис. 4,б), а для землетрясения 22.02.2016 г. с M = 4.1 наблюдаются всего 2 пониженных дневных минимума (см. рис. 5). Для землетрясений с $\mathrm{M} \approx 4$ обнаруженные перед ними аномалии слабо отличаются от естественных, и их связь с землетрясениями может быть оспорена. Но проявление аномалий в совокупности нескольких параметров и особенно исчезновение эффектов при отклонении от направления на эпицентр свидетельствует в пользу наличия такой связи.

Для случая землетрясения 12.12.2005 г. есть возможность сравнить полученные здесь результаты с результатами анализа уровня сигнала с частотой 40 кГц (Кабанов, Хасанов, 2016). На рис. 6 первый вечерний выброс ССП (5) начинается в промежутке от 17 до 18 ч. На рис. 4 11.12.2005 г. сразу после 18 ч наблюдается пониженный вечерний минимум уровня сигнала, явно для станции «Стекольный», и чуть заметно, по сравнению с предыдущими сутками, для станции «Сеймчан», для которой трасса распространения сигнала проходит через район землетрясения (Кабанов, Хасанов, 2016). Но для Сеймчана понижение значения вечернего минимума происходит еще 10.12.2005 г. Таким образом, полученные здесь при анализе ССП атмосфериков результаты подтверждают значимость дополнительных аномалий во временном распределении уровня сигнала с частотой 40 кГц, приведенных в работе (Кабанов, Хасанов, 2016).
Во всех рассмотренных случаях дополнительная информация о месте расположения землетрясения получена при использовании селекции по углу прихода атмосфериков на основе данных двух станций. При отсутствии селекции по углу некоторая информация о месте ожидаемого землетрясения требует данных трех станций (Кабанов, Шарафутдинов, 2013). Разумеется, более качественная селекция по углу прихода может быть достигнута при использовании трех и более станций. Это является требованием в случае создания действующей системы обнаружения предвестников землетрясений. Также обнаружение предвестников землетрясений с $\mathrm{M}<5$ требует обязательного использования угловой селекции приходящих атмосфериков и привлечения данных нескольких станций, поскольку в рассмотренных случаях аномалии ССП, локализованные перед землетрясениями с $\mathrm{M}<5$ при регистрации на двух станциях, не слишком сильно отличаются от естественных флуктуаций временного распределения ССП.

Обнаруженные аномалии поведения ССП перед землетрясениями с $\mathrm{M}<5$ не столько значимы как предвестники, сколько служат иллюстрацией использования многопараметрического анализа временной зависимости ССП. Для серии землетрясений на о. Кюсю (максимальная $\mathrm{M}=7.4$ ) были выявлены аномалии в нескольких параметрах временного распределения ССП: временной зависимости дневных минимумов, общем уровне отклонений от квазигармонической формы, выбросах в дневное время. Сочетание особенностей поведения этих параметров оказалось уникальным для всего периода непрерывных наблюдений (2012-2016 гг.). И некоторые из этих особенностей обнаружились и перед землетрясениями с $\mathrm{M}<5$ после применения угловой селекции. Для самого слабого из рассмотренных землетрясений в целях придания аномалиям значимости потребовалось введение еще одного параметра - уровня (выброса) ССП в вечернее время, необычность поведения которого была ранее обнаружена перед землетрясением 12.12.2005 г. И, в свою очередь, новая информация о поведении этого параметра была получена после применения угловой селекции к обработке данных этого землетрясения. Успех применения многопараметрического анализа обусловлен квазирегулярным (можно сказать - квазисинусоидальным, хотя длительность положительных и отрицательных полупериодов может существенно отличаться) видом неискаженной временной зависимости ССП. Поэтому удается обнаружить несколько типов искажений такой зависимости.

В случае исследования АА, результаты которого приведены в работах (Муллаяров и др., 
2011; Mullayarov et al., 2012), события, для которых предполагается связь с землетрясениями, представляют собой случаи возрастания амплитуды в выбранном временном отрезке для одного дня относительно других. Анализируемые нами параметры ССП также определяются с дискретностью один отсчет в день, но они относятся к разным периодам дня и количество используемой информации больше. Также для параметров наблюдаются непрерывные изменения (в течение нескольких суток), в отличие от анализа АА, где наблюдаются однодневные возрастания амплитуды. Представляется, что процесс изменений в ионосфере (которые и вызывают наблюдаемые эффекты в параметрах атмосфериков) перед землетрясениями в целом все же непрерывный, а не импульсный (в отличие от самого землетрясения). И наблюдаемое увеличение АА только за 12-14 дней перед землетрясениями (Mullayarov et al., 2012) в отсутствие существенных более близких эффектов, которые обнаруживаются нами, может свидетельствовать о большей чувствительности метода поиска аномалий во временном распределении ССП атмосфериков по сравнению с анализом поведения их амплитуды. Подтверждение связи с землетрясениями (Муллаяров и др., 2011; Mullayarov et al., 2012) делается со ссылкой на результаты азимутального сканирования, но такие результаты приведены непосредственно в статье (Муллаяров и др., 2011) только для одного землетрясения в Японии (11.09.2008 г., $\mathrm{M}=7.2$ ).

Нам также потребовалось азимутальное сканирование, чтобы подтвердить для землетрясений с $\mathrm{M}<5$ необычность обнаруженных перед ними аномалий. Таким образом, по сравнению с ранними исследованиями (Каталог..., 1991), в работах (Муллаяров и др., 2011; Mullayarov et al., 2012) и нами для подтверждения связи обнаруженных аномалий с землетрясениями, помимо локализации во времени, используется частичная (по углу прихода аномальных атмосфериков на станции) локализация обнаруженных эффектов в пространстве.

Основное различие наших результатов с полученными В. А. Муллаяровым с соавторами (2011; Mullayarov et al., 2012) заключается, как уже отмечалось, в характере обнаруживаемых аномалий. Если для первых авторов этот характер импульсный (однодневные возрастания АА), то в случае анализа ССП атмосфериков мы наблюдаем достаточно медленные изменения. Точки изменения свойств временной зависимости ССП на рис. 3-6 локализовать затруднительно. В работах (Муллаяров и др., 2011; Mullayarov et al., 2012) и нами рассмотрены случаи разных землетрясений, поэтому сопоставить по времени обнаруженные аномалии нельзя. Но при просмотре сохранившихся записей, полученных с помощью рассмотренной в статье (Шарафутдинов, Кабанов, 2007) сети, обнаружились данные для марта 2011 г. Это время входит в период подготовки серии землетрясений около о. Хонсю в мартеапреле 2011 г. (максимальное с $\mathrm{M}=8.8$, или 9 по зарубежным данным, 11-го марта), для которой в работе (Mullayarov et al., 2012) рассмотрены аномалии во временной зависимости АА. Там основные предвестники обнаружены в конце февраля, но и для начала марта имеется одна аномалия. В (Mullayarov et al., 2012) 5 марта после 24:00 UT отмечается кратковременный (часовой) всплеск AА, который, однако, авторы не относят к предвестникам из-за его кратковременности.

На рис. 7 отражен результат анализа наших записей для 02-23.03.2011 г. Мы не привели его в предыдущем разделе, поскольку для данного землетрясения угловая селекция дает довольно странные результаты, но сейчас этот рисунок нужен для сравнения результатов анализа ССП и АА. На рис. 7 показано временное распределение ССП для станции «Стекольный», полученное с использованием данных станции «Омчак» при отборе атмосфериков, приходящих из сектора углов юг - юго-запад $\left(45^{\circ}\right)$. На рис. 7 присутствует выброс ССП (выброс 1) примерно часовой длительности, но с максимумом после 15:00 LT 6 марта, т. е. на 3 ч позже, чем для AA в статье (Mullayarov et al., 2012). Выброс превышает средний уровень ночных максимумов ССП более чем в 2 раза. Было также выполнено азимутальное сканирование с использованием более узкого сектора углов (7-8 $)$. Максимальное значение выброса в 5.5 дБ было получено для отклонения в $40^{\circ}$ от южного направления к западу. Но обнаружился еще один максимум, правда, на 2.6 дБ ниже, для отклонения в $83^{\circ}$, т. е. для почти западного направления. Поэтому мы назвали результат угловой селекции странным, направление на землетрясение смещено к востоку (на $29^{\circ}$ относительно максимума выброса), и максимальные амплитуды выброса 6 марта наблюдаются для юго-западного и даже западного направления.

Выбросу предшествует резкий спад ночного максимума (около 2 дБ). Ночной максимум перед выбросом достигает минимального значения для северо-западного направления. При этом сохраняется заметная величина выброса 6 марта (примерно только на 1 дБ ниже, чем на рис. 7). На рис. 7 обнаруживается еще один выброс (выброс 2) в конце ночи 18 марта (ровно посередине периода отсутствия землетрясений), но ночные максимумы ССП рядом с ним обычные. Если считать выбросы случайными, то интенсивность их потока примерно $0.002 \mathrm{ч}^{-1}$ и вероятность попадания в небольшой временной интервал после всплеска АА, отмеченного в статье (Mullayarov et al., 2012), менее 1\%. Заметим, что 


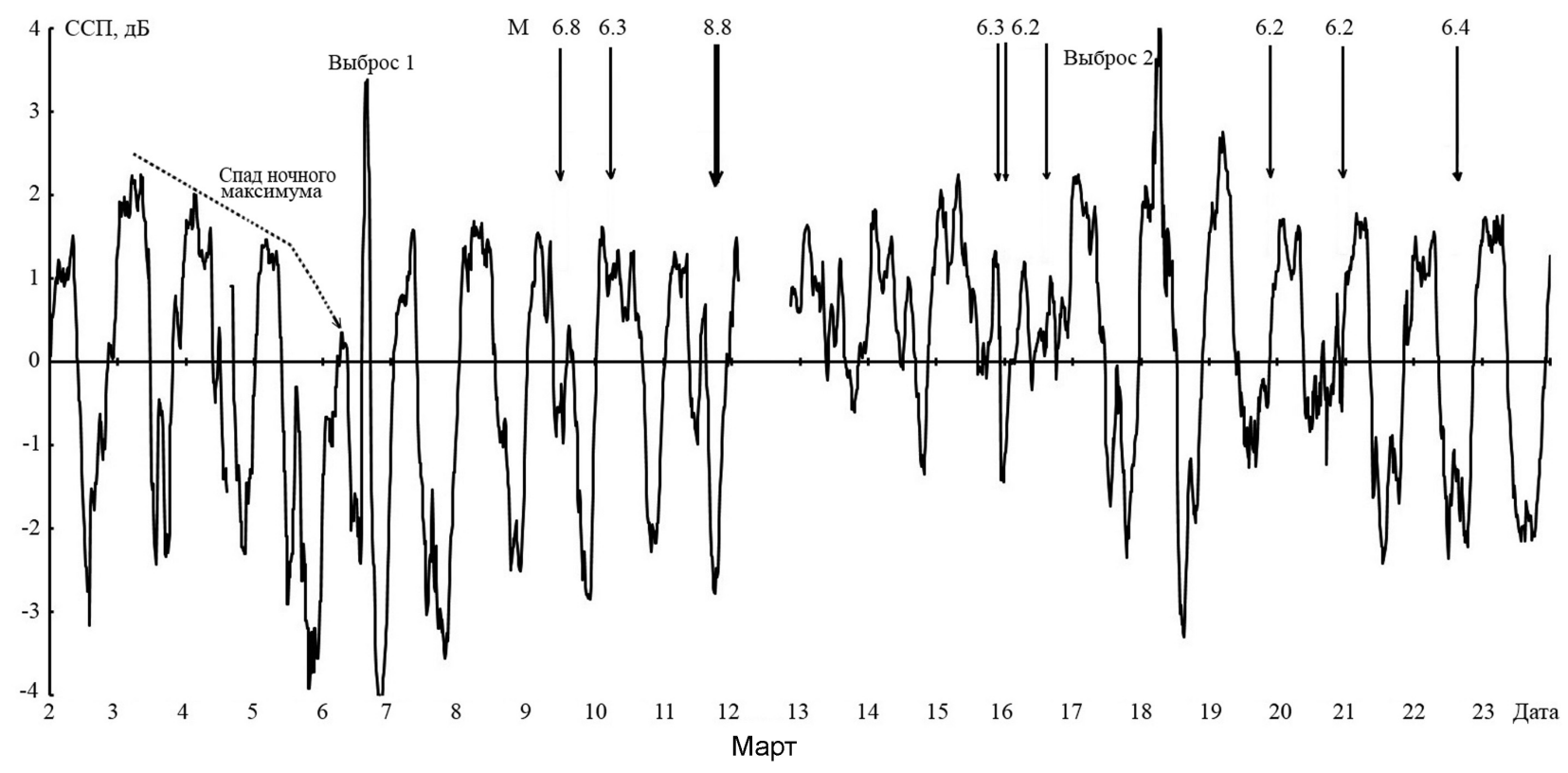

Рис. 7. Временное распределение ССП атмосфериков, приходящих из сектора углов юг - юго-запад, для 0223.03.2011 г.

Fig. 7. Temporal distributions of the SDR for atmospherics coming from the sector of angles south-southwest for March 2-23, 2011

выброс 18 марта имеет широкий $\left(45^{\circ}\right)$ максимум для направлений в сторону землетрясения, что не является странным, хотя центр этого максимума все же смещен на $12^{\circ}$ к востоку. Возможно, все это связано с нахождением станций в зоне возникших перед землетрясением ионосферных искажений, что показано в конце обсуждения, и аномалии наиболее ярки для атмосфериков, проходящих не над эпицентром, а в районе границ зоны ионосферных возмущений. Так, в работе (Кабанов, Шарафутдинов, 2013) для землетрясения 03.08.2010 г. наибольшие аномальные изменения ССП перед землетрясением наблюдаются в Сеймчане, предположительно находящемся в районе границы зоны ионосферных возмущений (Кабанов, Шарафутдинов, 2012). Этим можно объяснить задержку изменений ССП относительно АА. Если всплеск АА наблюдается для атмосфериков, приходящих с направления на эпицентр, то выброс ССП 6 марта может быть связан с изменениями в районе границ зоны ионосферных возмущений. А выброс 18 марта может быть обусловлен исчезновением зоны ионосферных возмущений вблизи станций. Но это все предположения, которые требуют отдельного дополнительного анализа.

Кроме эффектов в параметрах атмосфериков, на время появления всплесков АА и ССП приходится начало увеличения общей электронной концентрации в ионосфере, отмеченное на Fig. 4, $b$ в статье (Ouzounov et al., 2011) как предвестник. Хотя последний параметр в основном определяется верхней ионосферой, в то время как парамет- ры атмосфериков зависят от состояния нижней ионосферы, совпадение наблюдаемых эффектов по времени свидетельствует о начале общих ионосферных изменений. Если в случае АА эффект для рассматриваемого периода времени выражен в коротком всплеске (хотя в работе (Mullayarov et al., 2012) сообщается и о некотором общем увеличении АА с 5 марта), то выбросу ССП предшествует, как уже отмечалось, заметный спад ночного максимума. Импульсные изменения ССП сопутствуют более медленным.

Если в случае серии землетрясений в Японии в 2011 г. найден момент в поведении ССП, соответствующий всплескам АА в статье (Муллаяров и др., 2011) и (Mullayarov et al., 2012), то в случае ceрии 2016 г., на рис. 3 обособленных от других аномалий ССП не обнаруживается. Возможно, это связано с разным положением станций относительно зоны возможных ионосферных искажений. В случае землетрясений 2016 г. до нее более 1500 км, а в

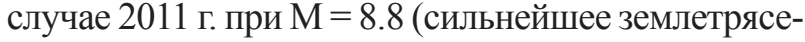
ние 11 марта) радиус зоны составит 6000 км, и она далеко перекрывает расположение станций. Для рассмотренных здесь землетрясений в случае землетрясения 22.02.2016 г. станции также находятся в зоне возможных ионосферных искажений и на соответствующем рис. 5 за 3-4 сут перед землетрясением наблюдаются узкие выбросы ССП с большой амплитудой.

В данной работе мы рассматриваем не все землетрясения, а только относящиеся к случаям эффективности использования угловой се- 
лекции. Угловая селекция оказалась также полезна при анализе землетрясений на Тайване 2 и 6 февраля 2016 г. (Кабанов, 2019). Как видно из рассмотрения серии землетрясений около о. Хонсю в марте-апреле 2011 г., нахождение станций в зоне ионосферных искажений затрудняет понимание получаемых результатов. Аналогичная ситуация имеет место с глубокофокусным (600 км) землетрясением в Охотском море с $\mathrm{M}=7.7$, произошедшим 24 мая 2013 г. Кроме того, имеется пропуск в данных 6-15 мая. Для этого землетрясения удалось обнаружить выбросы ССП, наблюдаемые для самых южных атмосфериков (сектор приблизительно $40^{\circ}$ ), но отсутствующие для всех южных. Наблюдаются дневные выбросы за 3 и 1 сут (самый большой) до и 2 сут после землетрясения и еще вечерний после дневного за 1 сут. До этого таких выбросов не было, а после есть более слабые. Наличие выбросов до и после землетрясения является сходной чертой аналогично выбросам, связанным с землетрясением 11 марта 2011 г. Также перед землетрясением наблюдаются пониженные ночные максимумы. Такие максимумы имеют место и перед уже упомянутым землетрясением 6 февраля 2016 г., так что определенная вероятность связи имеющихся эффектов с землетрясением есть.

На основе выполненных исследований можно сделать следующие выводы:

угловая селекция атмосфериков позволяет обнаружить дополнительные аномалии во временном распределении ССП перед предстоящим землетрясением;

при использовании угловой селекции и комплексного анализа совокупности особенностей временной зависимости ССП можно обнаружить предвестники землетрясений с $\mathrm{M} \sim 4$;

угловая селекция дает дополнительное подтверждение связи обнаруженных аномалий с землетрясениями;

результаты анализа ССП частично коррелируют с полученными другими исследователями.

\section{ЛИТЕРАТУРА}

Захаренкова И. Е., Шагимуратов И. И., Кранковски А., Лаговский А. Ф. Ионосферные аномалии, наблюдаемые в GPS TEC измерениях перед землетрясением в Греции 8 января 2006 г. (М6.8) // Исследовано в России [Электрон. ресурс]. 2006. C. 1047-1055. http:// zhurnal.ape.relarn.ru/artucles/2006/110.pdf

Кабанов В. В., Шарафутдинов В. М. Аппаратурные комплексы региональной сети сейсмоэлектромагнитного мониторинга на северо-востоке России // Приборы и техника эксперимента. 2007. № 2. С. 152-153.

Кабанов В. В., Шарафутдинов В. М. Вариации спектральной плотности мощности атмосфериков в полосе частот 8-40 кГц в период подготовки земле- трясений // Геомагнетизм и аэрономия. 2013. Т. 53, № 4. С. 567-574.

Кабанов В. В. Вариации спектральной плотности мощности импульсных сигналов грозовых разрядов в полосе частот 12-40 кГц, связанные с землетрясениями в Японии и на Тайване // Геомагнетизм и аэрономия. 2019. Т. 59, № 1. С. 83-97.

Кабанов В. В., Хасанов И. М. Особенности амплитудных флуктуаций сигнала радиостанции с частотой 40 кГц в Магаданской области в сейсмоактивные периоды // Вестник СВНЦ ДВО РАН. 2016. № 3. С. 55-62.

Кабанов В. В. Результаты оперативного анализа аномалий электромагнитного поля в полосе 8-40 кГц в период подготовки произошедшего 20.01.2013 на юго-востоке Якутии землетрясения с магнитудой 5.6 // Фундаментальные исследования. 2013. № 4 (5). С. 1109-1113.

Кабанов В. В., Шарафутдинов В. М. Соотношение спектральных плотностей естественных электромагнитных сигналов как объект для изучения возможности выделения сейсмоэлектромагнитных эффектов на Северо-Востоке России // Вестник СВНЦ ДВО РАН. 2012. № 4. C. 16-22.

Каталог импульсных электромагнитных предвестников землетрясений / отв. ред. С. И. Зубков. М. : ИФЗ АН СССР, 1991. 128 с.

Муллаяров В. А., Абзалетдинова Л. М., Аргунов B. B., Корсаков A. A. Вариации параметров грозовых электромагнитных сигналов на трассах, проходящих над областями землетрясений // Геомагнетизм и аэрономия. 2011. Т. 51, № 6. С. 841-851.

Муллаяров В. А., Козлов В. И., Амбурский А. В. Проявление землетрясений на трассах распространения ОНЧ-радиошумов и импульсных сигналов по наблюдениям в Якутске // Вулканология и сейсмология. 2007. № 4. С. 69-78.

Пулинеи С. А., Бондур В. Г., Цидилина М. Н., Гапонова М. В. Проверка концепции сейсмо-ионосферных связей в спокойных гелиогеомагнитных условиях на примере Венчуаньского землетрясения в Китае 12 мая 2008 г. // Геомагнетизм и аэрономия. 2010. Т. 50, № 2. C. 240-252.

Смирнов В. М. Интерпретация ионосферных возмущений в период слабых землетрясений // Исследовано в России [Электрон. ресурс]. 2003. № 12. С. 121129. http://zhurnal.ape. relarn.ru/ artucles/2003/012.pdf

Шарафутдинов В. М., Кабанов В. В. Разработка и создание региональной сети электромагнитного мониторинга землетрясений в ОНЧ-диапазоне на Северо-Востоке России // Вестник СВНЦ ДВО РАН. 2007. № 3. C. 10-16.

Mullayarov V.A., Argunov V. V., Abzaletdinova L. M., Kozlov V. I. Ionospheric effects of earthquakes in Japan in March 2011 obtained from observations of lightning electromagnetic radio signals // Nat. Hazards Earth Syst. Sci. 2012. Vol. 12. P. 3181-3190. DOI: 10.5194/nhess-12-3181-2012.

Ouzounov D., Pulinets S., Romanov A., Tsybulya K., Davidenko D., Kafatos M., Taylor P. T. Atmosphere-ionosphere response to the M9 Tohoku earthquake revealed by multi-instrument space-borne and ground observations : Preliminary results // Earthquake Sci. 2011. 24. P. 557-564. DOI: 10.1007/s11589-011-0817-z 


\title{
ANOMALIES IN THE TEMPORAL DISTRIBUTION OF THE ATMOSPHERIC SPECTRAL DENSITY RATIO IN THE EARTHQUAKES PREPARATION PERIOD WHILE USING THE SELECTION BY THE ARRIVAL ANGLE
}

\author{
V. V. Kabanov, I. M. Khasanov
}

\begin{abstract}
North-East Interdisciplinary Scientific Research Institute n. a. N. A. Shilo, FEB RAS, Magadan
When analyzing earthquake data with magnitude $M=5.6$, which occurred in the southeast of Yakutia on January 20, 2013, with the use of angular selection of incoming atmospherics, additional precursors of this earthquake have been discovered, the nearest one 10 minutes before the shock. The analysis of an earthquake series on the island of Kyushu (April 2016) exposed a set of anomalies in the temporal distribution of the spectral density ratio (SDR) of the natural electromagnetic signals (atmospherics) for the upper and lower sub-bands of the received frequency band $(8-40 \mathrm{kHz})$ of the electromagnetic field. Elements of this set of anomalies were found in the temporal distribution of the SDR of the atmospherics arriving from the direction to the epicenter, before three earthquakes with $\mathrm{M}<5$, which occurred at distances of 60-220 km from Magadan. Before the earthquake on May 7, 2016, with $M=4.7$, there is a period of lowered daily minimums of the SDR and of the SDR bursts. The earthquake on February 22, 2016, with $\mathrm{M}=4.1$, is preceded by a short period of lowered daily minimums and an evening SDR burst. Before the earthquake on December 12, 2005, there were increasing evening SDR bursts. The use of atmospheric angular selection in the estimation of the SDR permits to reveal additional anomalies in the SDR time distribution before the forthcoming earthquake and to detect possible precursors before earthquakes with $\mathrm{M} \approx 4$.
\end{abstract}

Keywords: earthquakes, electromagnetic signals, atmospherics, spectral density ratio, precursors.

\section{REFERENCES}

Catalog of Impulsive Electromagnetic Precursors of Earthquakes, 1991, Ed. S. I. Zubkov, Moscow, IFZ AN USSR [In Russian].

Kabanov, $V . V$., 2013, Results of Operative Analysis of the Electromagnetic Field Anomalies in the $8-40 \mathrm{kHz}$ Frequency Band during Preparation of the Earthquake 20.01.2013 with Magnitude 5.6 in Southeast Yakutia, Fundamental Research, 4, 5, 1109-1113 [In Russian].

Kabanov, V. V., 2019, Variations in the Power Spectral Density of Thunderstorm Discharge Pulses in the Frequency Band of 12-40 kHz Associated with Earthquakes in Japan and Taiwan, Geomagnetism and Aeronomy, 59, 1, 83-97 [In Russian].

Kabanov V. V.; Khasanov I. M., 2016, Peculiarities of Amplitude Fluctuations of the Radiostation Signal with Frequency $40 \mathrm{kHz}$ in Magadan Oblast during Seismic Acticities, Vestnik NESC FEB RAS, 3, 55-62 [In Russian].

Kabanov, V. V.; Sharafutdinov, V. M., 2007, Hardware Systems at the Regional Network of Seismoelectromagnetic Monitoring in the North-East of Russia, Instruments and Experimental Techniques, 2, 152-153 [In Russian].

Kabanov, V. V.; Sharafutdinov, V. M., 2012, Spectral Density Relationships of Natural Electromagnetic Signals as a Study Object to Investigate Opportunities for Distinguishing Seismic Electromagnetic Effects in the North-East of Russia, Vestnik NESC FEB RAS, 4, 16-22 [In Russian].

Kabanov, V. V.; Sharafutdinov, V. M., 2013, Variations in the Atmospherics Power Spectrum Density in the Frequency Band 8-40 kHz during Earthquake Preparation, Geomagnetism and Aeronomy, 53, 4, 567-574 [In Russian].

Mullayarov, V.A.; Abzaletdinova, L.M.; Argunov, V.V.; Korsakov, A. A., 2011, Variations in the Parameters of Thunderstorm Electromagnetic Signals on Paths over Earthquakes Regions, Ibid., 51, 825-834 [In Russian].

Mullayarov, V. A.; Argunov, V. V.; Abzaletdinova, L. M.; Kozlov, V. I., 2012, Ionospheric Effects of Earth- quakes in Japan in March 2011 Obtained from Observations of Lightning Electromagnetic Radio Signals, Nat. Hazards Earth Syst. Sci., 12, 3181-3190, DOI: 10.5194/ nhess-12-3181-2012

Mullayarov, V. A.; Kozlov, V. I.; Amburskii, A. V., 2007, Earthquake Effects along Paths of VLF Radio Noise and Impulsive Signals as Observed in Yakutsk, Journal of Volcanology and Seismology, 4, 69-78 [In Russian].

Ouzounov, D.; Pulinets, S.; Romanov, A.; Tsybulya, K.; Davidenko, D.; Kafatos, M.; Taylor, P. T., 2011, Atmosphere-Ionosphere Response to the M9 Tohoku Earthquake Revealed by Multi-Instrument Space-Borne and Ground Observations: Preliminary Results, Earthquake Sci., 24, 557-564, DOI: 10.1007/s11589-011-0817-z

Pulinets, S. A.; Bondur, V. G.; Tsidilina, M. N.; Gaponova, $M . V ., 2010$, Verification of the Concept of Seismoionospheric Coupling under Quiet Heliogeomagnetic Conditions, Exemplified by the Wenchuan Earthquake in China on May 12, 2008, Geomagnetism and Aeronomy, 50, 231-242 [In Russian].

Sharafutdinov, V. M.; Kabanov, V. V., 2007, Development and Creation of the Regional Network of Earthquake Electromagnetic Monitoring in the VLF Range in the North-East of Russia, Vestnik NESC FEB RAS, 3, 1016 [In Russian].

Smirnov, V. M., 2003, Interpretation of Ionospheric Disturbances in the Period of Weak Earthquakes, Investigated in Russia [Electron. Resource], 12, 121129, http://zhurnal.ape.relarn.ru/artucles/2003/012.pdf [In Russian].

Zakharenkova, I. E.; Shagimuratov, I. I.; Krankovsky, A.; Lagovsky, A. F., 2006, Ionospheric Anomalies Observed in GPS TEC Measurements before the Earthquake in Greece on January 8, 2006 (M6.8), Investigated in Russia [Electron. Resource], 1047-1055, http://zhurnal.ape. relarn.ru/artucles/2006/110.pdf [In Russian]. 